\title{
Estimation of the mean tree height of forest stands by photogrammetric measurement using digital aerial images of high spatial resolution
}

\author{
I. Balenović, A. Seletković, R. Pernar, A. Jazbec
}

Balenović I., Seletković A., Pernar R., Jazbec A., 2015. Estimation of the mean tree height of forest stands by photogrammetric measurement using digital aerial images of high spatial resolution. Ann. For. Res. 58(1): 125-143.

\begin{abstract}
Tree height is one of the more fundamental measurements in forest inventories. In addition to classical field measurements, tree height may be estimated by remote sensing methods, such as by photogrammetric measurements of aerial images. Since it has been found and generally accepted that the extraction of forest and tree data from classical analogue aerial photographs has certain limitations, especially in the densely canopied forests, the usefulness of photogrammetric-based forest inventory in many countries remains a controversial issue. Therefore, this paper focuses on investigating the possibility of applying digital photogrammetric method to estimate mean stand height. Photogrammetric stereo-measurements of tree height were conducted on colour infrared images of high spatial resolution (ground sample distance - GSD - of $30 \mathrm{~cm}$ and $10 \mathrm{~cm}$ ) using a digital photogrammetric workstation. The height of each tree within 183 sample plots (14 subcompartments) were calculated as the difference between the tree top elevations determined with the aerial images and the corresponding tree bottom elevations determined from the digital terrain model. To compare the photogrammetric- and field-estimated mean stand heights, the mean plot heights were calculated for both photogrammetric and field estimates of tree heights. Repeated measurements using ANOVA testing did not reveal a statistically significant difference $(p>0.05)$ between the field-estimated and photogrammetric-estimated mean stand heights using the $30 \mathrm{~cm}$ and $10 \mathrm{~cm}$ GSD digital aerial images. Deviations of the mean stand heights estimated using the images of both spatial resolutions were similar to the field-estimated heights. Using the $30 \mathrm{~cm}$ images the deviations of the photogrammetrically estimated mean stand height amounted to $0.35 \mathrm{~m}(1.59 \%)$ on average, whereas using the $10 \mathrm{~cm}$ images the deviations amounted to $0.31 \mathrm{~m}(1.41 \%)$ compared to the field estimation. Therefore, it can be concluded that the $30 \mathrm{~cm}$ GSD aerial images allow for the photogrammetric measurement of mean stand heights with accuracy similar to $10 \mathrm{~cm}$ GSD aerial images. In addition, $30 \mathrm{~cm}$ GSD aerial images are more favourable financially since the same area of interest could be covered with a considerably smaller number of images than of the $10 \mathrm{~cm}$ GSD aerial images. Keywords tree height, mean stand height, stereo-measurement, digital aerial images, digital photogrammetric workstation.
\end{abstract}


Authors. Ivan Balenović (ivanb@sumins.hr) - Croatian Forest Research Institute, Zagreb, Croatia; Ante Seletković, Renata Pernar, Anamarija Jazbec - University of Zagreb, Faculty of Forestry, Zagreb, Croatia.

Manuscript received May 23, 2014; revised October 28, 2014; accepted January 01, 2015; online first January 30, 2015.

\section{Introduction}

Tree height is an important variable for the quantitative description of trees and stands that can determine the site quality of a stand and estimate parameters such as: growing stock, biomass, carbon stock, and stand growth, etc.. There are a number of instruments and methods for estimating the height of standing trees. In addition to the classical field methods, tree and stand heights may also be estimated by remote sensing methods (van Laar \& Akça 2007). Widely used remote sensing methods for estimating tree heights include photogrammetric measurements of aerial images and more recently LiDAR (light detection and ranging) technology. Estimating the height of an individual tree and mean stand height, which is more common, by photogrammetric measurements of stereo pairs using classical analogue aerial photographs from analogue or analytical stereo instruments (analogue and analytical photogrammetry) has been studied by a number of authors (e.g., Worley \& Landis 1954, Benko 1993, Næsset 1996, Kovats 1997, Anttila 1998, Eid et al. 2004, Magnusson \& Fransson 2005). Aerial photographs and digital aerial images have become an integral part of forest inventories in a number of countries (e.g., Finland, Norway, Sweden, Canada) (Spencer \& Hall 1988, Næsset 2002a, Magnusson et al. 2007, Tuominen et al. 2014).

During a photogrammetric stereo-measurement of analogue aerial photographs, tree height is determined by placing stereo markers of the instrument on the top of the tree and ground next to the tree and the elevation difference between the two markers is then calculated as the height. The main disadvantage of this process is the limited potential of identifying the bottom of a tree in densely canopied stands if the terrain surface in the vicinity of the tree is not visible (Korpela 2004, Paine \& Kiser 2012). Another reason for the limited practical application is related to the amount of manual processing required when using the classical photogrammetric methods (Balenović et al. 2010, Paine \& Kiser 2012). Due to above-mentioned reasons it has been generally accepted that the extraction of forest and tree data from classical analogue aerial photographs has certain limitations, especially in the densely canopied forests. Therefore, except for the above-mentioned countries the usefulness of photogrammetric method for forest inventories remains a controversial issue (van Laar \& Akça 2007).

However, advancements in computer technology in the 1980s and 1990s have enhanced the development of remote sensing methods and techniques. Over the past thirty years, photogrammetry has also crossed a developmental path from analogue and analytical to digital photogrammetry, which has replaced analogue aerial photographs and analogue and analytical stereo instruments with digital aerial images and digital photogrammetric workstations (DPWs) (Magnusson et al. 2007, Linder 2009). Current digital aerial photogrammetric cameras make it possible to capture digital aerial images of extremely high spatial resolution with ground sampling distance (GSD) values of only several centimetres (Sandau 2010). With the application of DPWs, a number of photogrammetric processes, such as the creation of digital terrain models (DTMs) or digital orthophotos, have generally become automated and the manipulation of aerial images has improved 
(Honkavaara et al. 2009, Lemmens 2011).

The development of digital photogrammetry has motivated foresters to undertake numerous research activities related to its application in forestry services. Based on a review of the research on the applications of digital photogrammetric method in forest inventories, Benko \& Balenović (2011) differentiated between (i) manual methods (e.g., Korpela 2004, Magnusson et al. 2007, Balenović et al. 2011, 2012, Hoxha 2012, Ferdinent \& Padmanaban 2013); (ii) automated methods of photogrammetric measurement and interpretation of digital aerial images using a computer or DPW (e.g., Næsset 2002a, Korpela 2004, Korpela \& Anttila 2004, Zagalikis et al. 2005, Bohlin et al. 2012). Disadvantages of manual methods, such as the required expertise of the workforce, need for interpreters, increased time requirements, and subjectivity of interpreters (Meyer et al. 1996, Anttila 2005, Morgan et al. 2010), have made automated methods more attractive and interesting for researchers (Ke \& Quackenbush 2011). However, automatic methods are still lacking in terms of the accuracy of the results, such as when determining trees species and estimating the elements in a stand structure, which limits the potential of their operational (Hollaus et al. 2006, Balenović et al. 2011). Furthermore, continual progress in computer technology (DPWs) and the development of user-friendly photogrammetric software provide sufficient reasons for further studies on the application of digital photogrammetric methods (both automated and manual) in operational forestry.

The main goal of this paper was to investigate the possibility of applying a manual digital photogrammetric method to estimate mean stand height. For this purpose, photogrammetric measurements of tree heights using stereo models of colour infrared (CIR) digital aerial images of high spatial resolutions $(10 \mathrm{~cm}$ GSD and $30 \mathrm{~cm}$ GSD) were performed by DPW. The DPW results and classical field estimates were compared and analysed to determine whether the applied photogrammetric measurement method is applicable in operational forest inventory. In addition, the spatial resolution (10 $\mathrm{cm}$ GSD and $30 \mathrm{~cm}$ GSD) of the applied aerial images was investigated to determine if it affects the accuracy of the obtained results and the extent of the effects. Furthermore, the purpose of this study was also to provide the procedure to facilitate data collection in Croatia and other countries where remote sensing methods are not an integral part of forest inventory.

\section{Material and methods}

\section{Study area}

The research was conducted in a privately owned forest in the management unit Donja Kupčina - Pisarovina, which is located $25 \mathrm{~km}$ south of Zagreb (Croatia). Covering the total area of 1152.77 ha, the management unit extends from $45^{\circ} 31^{\prime} 52^{\prime \prime}$ to $45^{\circ} 36^{\prime} 18^{\prime \prime}$ north latitude and from $15^{\circ} 45^{\prime} 19^{\prime \prime}$ to $15^{\circ} 55^{\prime} 27^{\prime \prime}$ east longitude (Transverse Mercator projection, Bessel 1841 ellipsoid, Helmannskoegel datum). The study area for this research covers approximately 480 ha containing a total of six compartments and fourteen sub-compartments. Multiple aerial surveys were required to collect the imagery utilized in this study (Figure 1). The altitude of the area ranges from 100 to $160 \mathrm{~m}$ and slope from $0^{\circ}$ to $30^{\circ}$. The main tree species are sessile oak (Quercus petraea L.), European beech (Fagus sylvatica L.), common hornbeam (Carpinus betulus L.) and black alder (Alnus glutinosa (L.) Gaertn.). Other species present include poplars (Populus sp.), wild cherry (Prunus avium L.), black locust (Robinia pseudoacacia L.), European aspen (Populus tremula L.), and silver birch (Betula pendula Roth), etc. Above-mentioned species form even-aged (sessile oak management class) and the multi-aged stands (European beech and common hornbeam management 


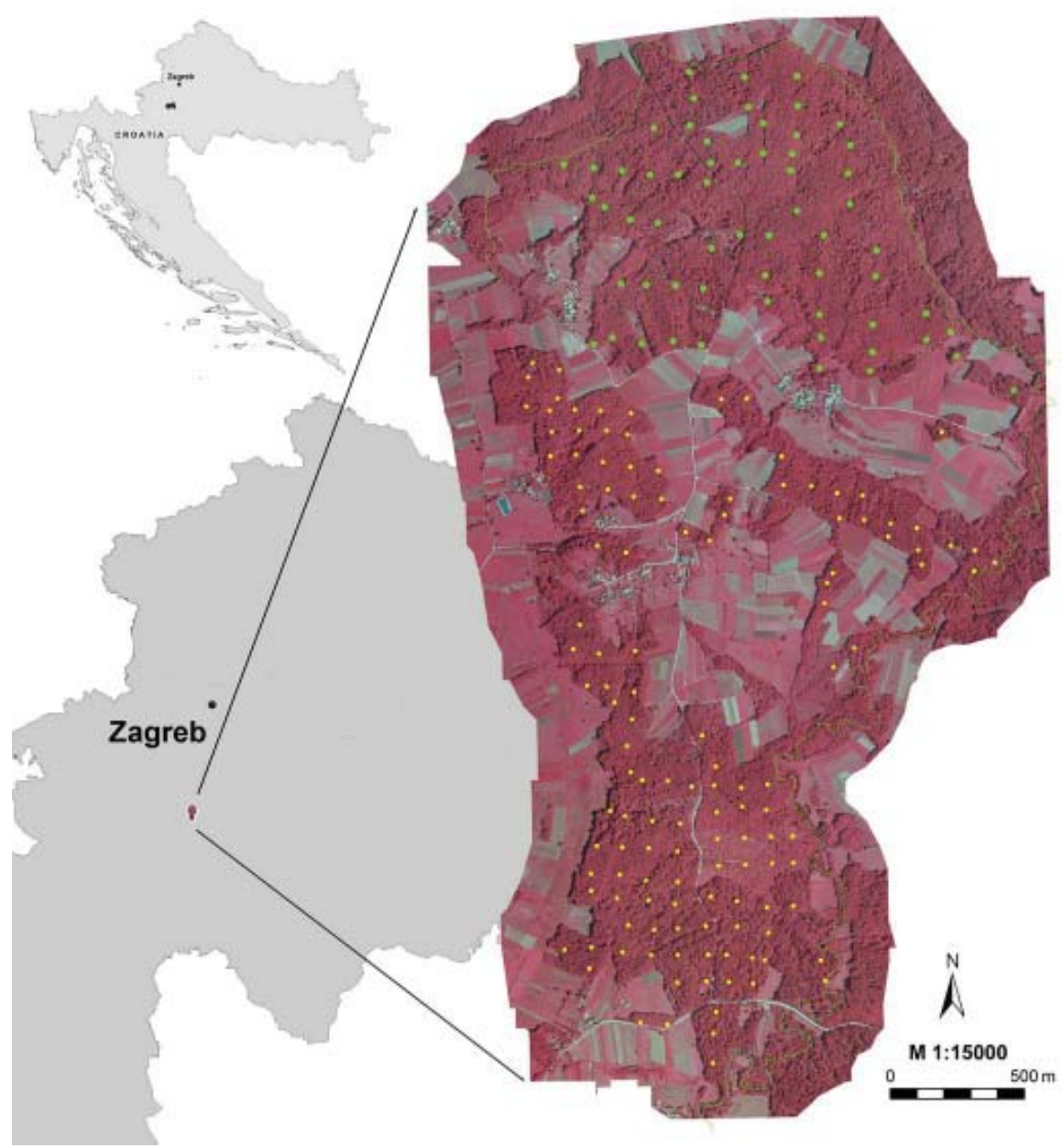

Figure 1 The location of the study area (left) and sample plot layout in the study area (right). Green circles represent plots of a $12 \mathrm{~m}$ radius, and yellow circles represent plots of an $8 \mathrm{~m}$ radius

classes). The multi-aged stands primarily consist of a series of even-aged stands in different developmental stages.

\section{Field data}

Field data were collected according to the valid Regulation on Forest Management (Official Gazzette 111/06, 141/08) during the spring and summer of 2009 . To satisfy the $2 \%$ minimum sampling intensity required by the regulations, a systematic pattern of circular sample plots was set in the form of $100 \times 100$ $\mathrm{m}, 100 \times 200 \mathrm{~m}$ or $200 \times 100 \mathrm{~m}$ square grids depending on the size and shape of subcompartments and the size of the plot. A total of 183 circular plots with radii of 8 or $12 \mathrm{~m}$ depend- ing on the stand density and age were set in the 14 selected subcompartments (267.29 ha), which formed a sampling area of 5.23 ha and a sampling intensity of $2.0 \%$. The diameter at breast height (dbh) of all of the trees in the sample plots above the taxation limit of $10 \mathrm{~cm}$ was measured by a calliper with a centimetre graduation. The spatial coordinates $(\mathrm{x}, \mathrm{y})$ of the sample plot centres were recorded with a GPS receiver, and subsequently were used to overlay upon the aerial images for conducting the photogrammetric measurements. The positional (horizontal) accuracy quoted by the manufacturer of the MobileMapper 6 GPS receiver (Magellan Navigation Inc, Santa Clara, California, USA) is $2-5 \mathrm{~m}$ for ideal conditions (e.g., open sky, a substantial number of avail- 
able satellites and their geometry, etc).

The field height of each tree $\left(h_{F}\right)$, whose $d b h$ was measured in the sample plots, was calculated by means of the constructed height curves fitted with Michailloff's function (Michailloff 1943) (eq. 1):

$h_{F}=b_{0}^{-\frac{b_{1}}{d b h}}+1.30$

where $b_{0}$ and $b_{1}$ are the fitting parameters. Due to its great flexibility, Michailoff's function is the most commonly used equation for fitting height curves in Croatian forestry (Pranjić \& Lukić 1997). In general, the use of height curves (height-dbh models) is a common practice in forestry (Arcangeli et al. 2013). The local height curves may provide the best unbiased estimates of tree height if they are based on a sufficient number of height measurements (van Laar \& Akça 2007). Data for fitting local height curves (dbhs and tree heights) were collected during additional measurement on a sample of 103 oak trees, 103 beech trees, 123 hornbeam trees and 50 alder trees. Tree heights were measured using a Vertex III hypsometer with a precision of $0.1 \mathrm{~m}$. An attempt was made to achieve a regular spatial distribution of sampled trees throughout the research area and equal participation of all of the diameter degrees of dbh distributions in the sample. The local height curves were constructed for the main tree species (Table 1) and used to calculate the heights of rare and sporadic secondary tree species. The height curve of the common hornbeam was used to calculate the heights of secondary tree species (wild cherry, black locust and European aspen) grouped in the other hardwood broadleaf category, whereas the height curve of the black alder was used to calculate the heights of all of the trees (poplar and silver birch) grouped in the other softwood broadleaf category.

\section{Photogrammetric data}

Aerial image acquisition and DTM generation. The CIR digital aerial images of the research area were collected using a Microsoft UltraCamX digital large-format aerial camera by Geofoto Ltd. (Zagreb, Croatia) during two aerial surveys in July 2009.

The UltraCamX is a multi-head camera consisting of eight camera heads. Four camera heads equipped with nine individual CCD sensors build large format panchromatic images by recording the visible part of the electromagnetic spectrum. Another set of four camera heads with individual CCD sensors collect the multispectral data, such as the colour information in the red, green, blue and near infrared bands of the spectrum. The high-resolution multispectral images are provided by pansharpening lower resolution multispectral data in post-processing. The resulting images have 14,430 by 9,420 pixels, and the pixel size is $7.2 \mu \mathrm{m}$. The principal distance (i.e., the focal length) of the camera is $100.5 \mathrm{~mm}$. Apart from a high geometric resolution, the UltraCamX provides images of a high radiometric resolu-

Table 1 Sample size $(N)$, fitting parameters $\left(b_{0}, b_{1}\right)$, determination $\left(R^{2}\right)$ coefficients and root mean square errors (RMSE) of the height curves of the main tree species fitted with Mihajlo's function (Michailloff 1943)

\begin{tabular}{llllll}
\hline Tree species & $N$ & $b_{0}$ & $b_{1}$ & $R^{2}$ & $\begin{array}{l}R M S E \\
(\mathrm{~m})\end{array}$ \\
\hline Sessile oak & 103 & 33.162 & 11.356 & 0.60 & 2.61 \\
European beech & 103 & 31.183 & 9.6982 & 0.69 & 2.85 \\
Common hornbeam & 123 & 28.131 & 7.7388 & 0.51 & 2.38 \\
Black alder & 50 & 31.285 & 10.9874 & 0.79 & 1.95 \\
\hline
\end{tabular}


tion ( $>12$ bit) (Gruber et al. 2008).

The initial 'high' aerial survey was conducted on July 18, 2009. The average flying height was 4,190 $\mathrm{m}$ above ground level, which provided a GSD of $30 \mathrm{~cm}$. In total, 7 CIR digital aerial images of $30 \mathrm{~cm}$ GSD were collected in a block structure ( 2 strips of 3 or 4 images per strip) with forward overlaps of $60 \%$ and side overlaps of $30 \%$ (Figure 2). The base of acquired images was $1130.4 \mathrm{~m}$, which resulted in a base-to-height ratio of 0.26 . The images were collected between 11:30 am and 14:00 pm local time $(\mathrm{UTC}+1)$ when the weather condi- tions were good (clear sky, no winds) and the solar elevation angle was $55-65^{\circ}$.

A 'low' aerial survey was conducted on July 22,2009 . The average flying height was 1,400 $\mathrm{m}$ above ground level, which provided a GSD of $10 \mathrm{~cm}$. The study area was covered by 21 CIR digital aerial images of $10 \mathrm{~cm}$ GSD. The images were collected in 2 strips ( 9 and $12 \mathrm{im}$ ages per strip) with forward overlaps of $60 \%$ and side overlaps of $30 \%$ (Figure 2). The base of acquired images was $376.8 \mathrm{~m}$, which resulted in a base-to-height ratio of 0.27 . The images were collected between 10:00 am and 12:00

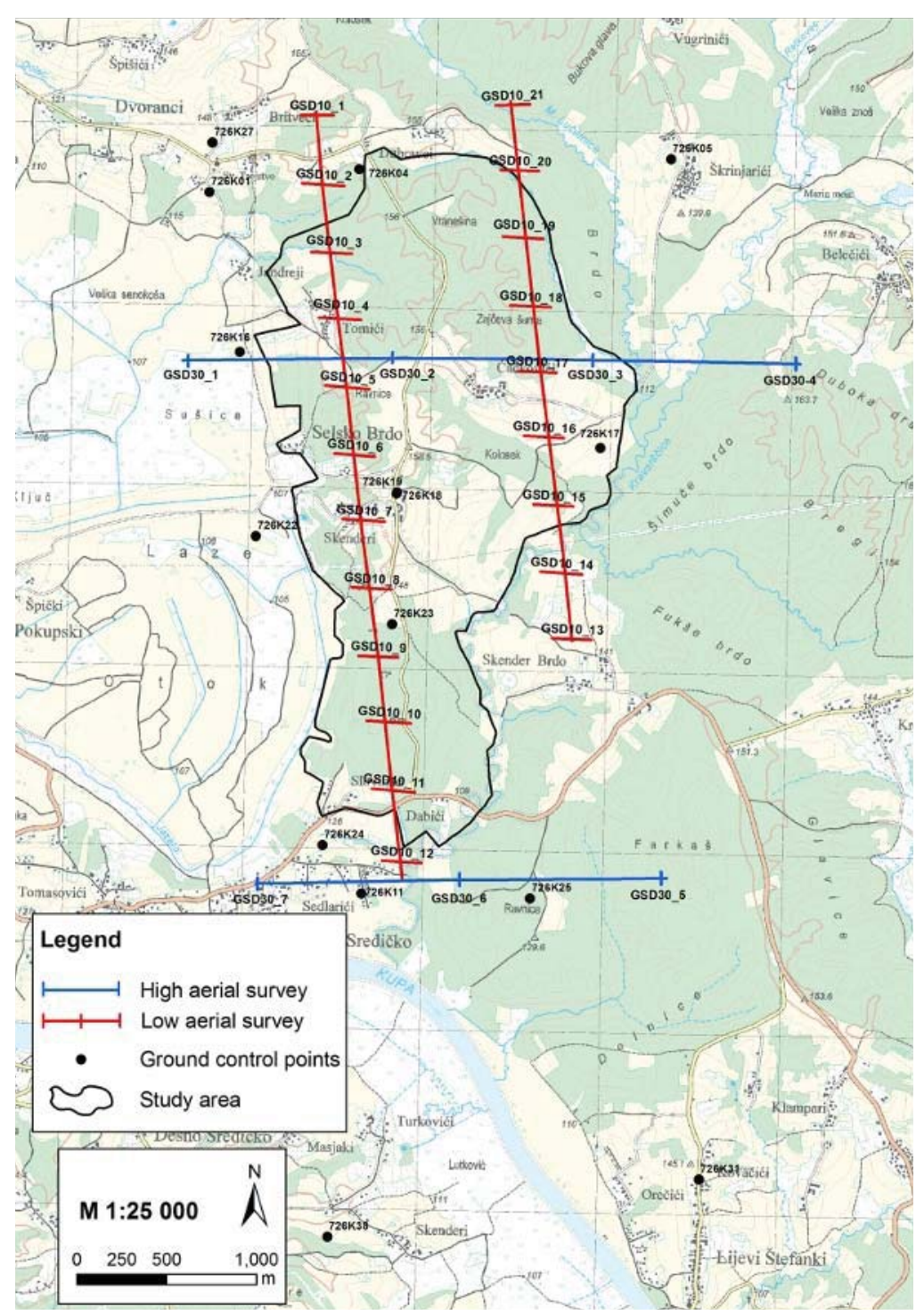

Figure 2 The flight plane overview of the conducted aerial surveys and location of the ground control points 
pm local time $(\mathrm{UTC}+1)$ when the weather conditions were good and the solar elevation angle was $55-65^{\circ}$.

To obtain CIR digital images of high radiometric and geometric quality, post-processing was performed on the collected raw image data using the camera specific Microsoft Office Processing Center software (Microsoft, Vexcel Imaging $\mathrm{GmbH}$, Graz, Austria). After each aerial survey, the raw image data consisted of sets of thirteen separate files (nine files of panchromatic images and four files of multispectral image). By post-processing (radiometric and geometric correction, pan-sharpening), each set of thirteen raw files was converted into one raster file with a CIR digital image of 10 or $30 \mathrm{~cm}$ GSD. In preparation for the DTM generation and photogrammetric stereomeasurement, such post-processed images were introduced into an automatic aerial triangulation (AAT) performed by the ImageStation Automatic Triangulation software module (Intergraph Corporation, Huntsville, Alabama, USA). An overview of the main parameters and the results of the AAT is presented in Table 2.

The digital terrain data (breaklines and mass points) for the DTM derivation were collected by stereo-mapping of the $10 \mathrm{~cm}$ GSD digital aerial images on the DPW ImageStation using the modules Feature Collection, Automatic Elevation and DTM Collection (version 6.0). From the collected digital terrain data, a triangulated irregular network was created, which was then used for DTM (raster grid) generation by the software Terrasolid Terra Modeler. The size of the interpolated grid was $25 \mathrm{~m}$ (Figure 3), and the vertical accuracy of the generated DTM was derived according to 15 ground control points and expressed with the root mean square error $\left(\mathrm{RMSE}_{\mathrm{z}}\right)$, which amounted to $0.04 \mathrm{~m}$.

The aerial triangulation and DTM generation were performed by Geofoto Ltd. according to the rules of the Croatian State Geodetic Administration (Product Specifications 301D130 and 301D150).

Photogrammetric measurement.The photogrammetric stereo-measurements of tree height were performed with the stereo models of CIR digital aerial images $(30 \mathrm{~cm}$ GSD and $10 \mathrm{~cm}$ GSD) using DPW with the PHOTOMOD Lite 4.4 photogrammetric software and Global Mapper v11.01 software. The stereoscopic view was produced by using the stereo-viewing DPW system (NVIDIA GeForce 9800 GT graphic card, Hyundai IT W220S stereo-monitor and Hyundai polarised interlaced stereo-glasses). A detailed description of the equipment and photogrammetric measurement methods is provided by Balenović et al. (2011).

In short, the initial photogrammetric measurement was conducted in the PHOTOMOD StereoDraw module. The photogrammetric plots were overlaid upon the aerial images based on the spatial coordinates $(\mathrm{x}, \mathrm{y})$ of the terrestrial sample plot centres recorded by the GPS receiver. The determination (interpretation) of tree species and crown tops was performed for each tree whose top fell inside the circular sample plot. The visual interpretation of tree species was based on the general appearance of tree crowns (crown form, structure and texture) and crown colour. The photo-interpreter had previously undergone training on the terrestrial plots with known tree species. Additionally, the findings from previous

Table 2 The main parameters and results of aerial triangulation and DTM generation

\begin{tabular}{|c|c|c|c|c|c|c|}
\hline $\begin{array}{l}\text { GSD } \\
(\mathrm{cm}) \\
\end{array}$ & Number of ground control points & $\begin{array}{l}R M S E_{X} \\
(\mathrm{~m})\end{array}$ & $\begin{array}{l}R M S E_{Y} \\
(\mathrm{~m})\end{array}$ & $\begin{array}{l}R M S E_{X Y} \\
(\mathrm{~m})\end{array}$ & $\begin{array}{l}R M S E_{Z} \\
(\mathrm{~m})\end{array}$ & $\begin{array}{l}\sigma_{O} \\
(\mu \mathrm{m})\end{array}$ \\
\hline 30 & 15 & 0.090 & 0.097 & 0.132 & 0.038 & 2.9 \\
\hline 10 & 15 & 0.121 & 0.088 & 0.150 & 0.020 & 2.9 \\
\hline
\end{tabular}




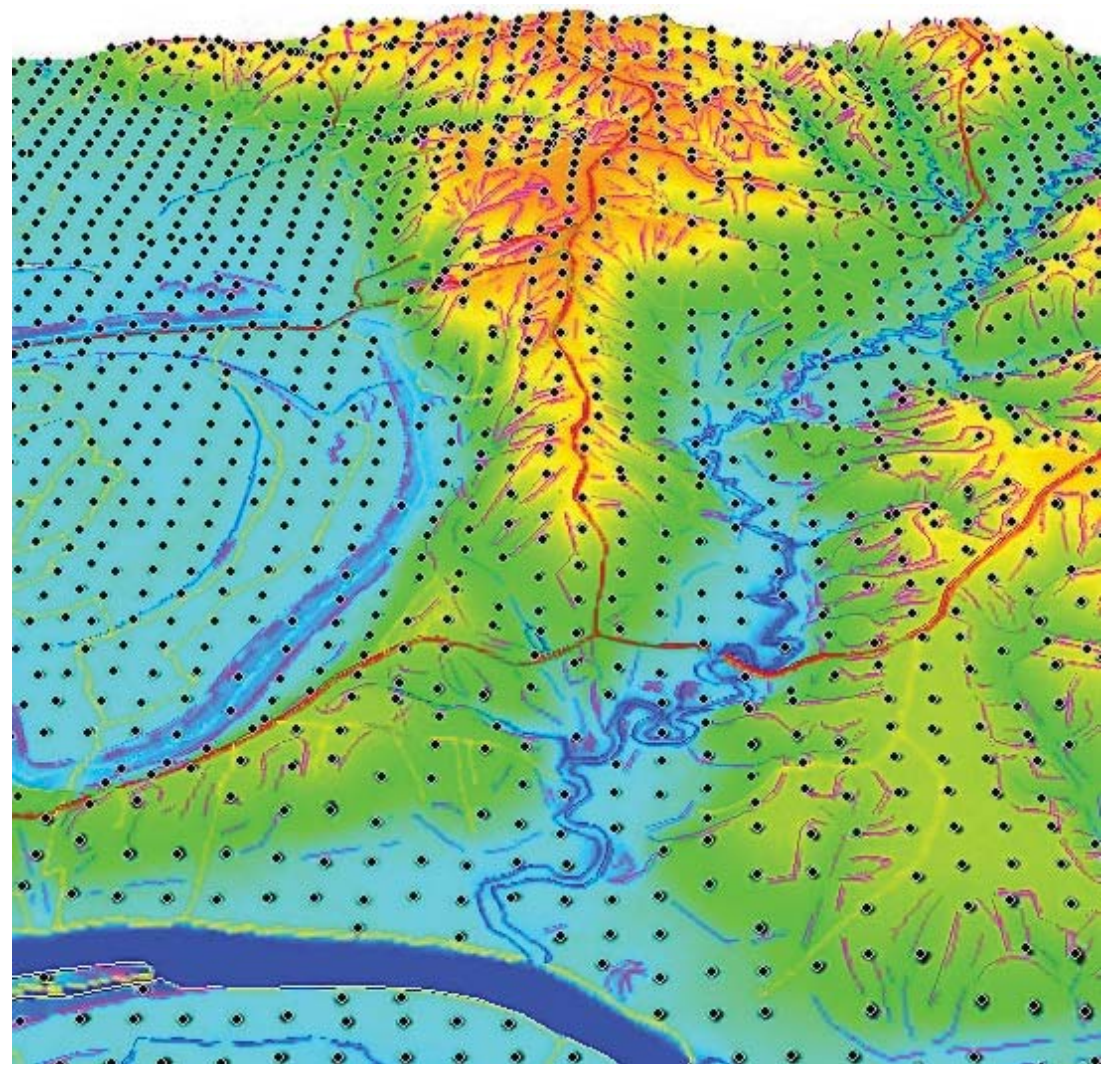

Figure 3 The digital terrain model of the study area, including an interpolated raster grid with digital terrain data (breaklines and mass points)

research (Pernar 1994, Pernar et al. 2007a, 2007b) on the methods of mapping particular tree species on CIR aerial images were also helpful. The interpreted secondary tree species were grouped among other hardwood broadleaf (OHB) and softwood broadleaf (OSB) species. The top of each tree in the plot was determined and marked manually by placing a stereo marker on the crown top and creating a $3 \mathrm{D}$ point object with the accompanying $\mathrm{x}, \mathrm{y}$ and $\mathrm{z}$ coordinates.

To obtain the data (elevation of tree tops and 'bottoms') required to calculate the tree heights, the objects (points of tree tops) collected in the StereoDraw module were loaded in the Global Mapper v11.01 software. The DTM of the study area was also loaded in the Global Mapper software and used as a basis for referencing the elevations of tree tops and tree 'bottoms.' The following steps were taken in the Global Mapper software: (i) the elevations of tree tops $\left(\mathrm{h}_{\mathrm{P}-\mathrm{t}}\right)$ were exported based on the previously loaded point objects; and (ii) the elevations of tree 'bottoms' $\left(\mathrm{h}_{\mathrm{P}-\mathrm{b}}\right)$, which were the elevations of the orthogonal projections of the tree tops on the ground - DTM, were determined and exported from the associated tree top points by the interpolation from the DTM. Finally, the photogrammetric height of each tree $\left(\mathrm{h}_{\mathrm{p}}\right)$ in the plot was calculated as the difference between tree top elevations determined in the stereo models of the CIR digital images $\left(\mathrm{h}_{\mathrm{P}-\mathrm{t}}\right)$ and the corresponding tree bottom elevations $\left(\mathrm{h}_{\mathrm{P}-\mathrm{b}}\right)$ determined from the DTM.

Data processing and analysis. The arithmetic mean tree height for each plot (hereafter referred to as mean plot height), estimated by field $\left(\bar{h}_{F-p l}\right)$ and photogrammetric measurements of the digital aerial images at $30 \mathrm{~cm}$ $\operatorname{GSD}\left(\bar{h}_{P 30-p l}\right)$ and $10 \mathrm{~cm}$ GSD $\left(\bar{h}_{P 10-p l}\right)$ was calculated for statistical data processing and comparisons. Additionally, the arithmetic mean tree height of each subcompartment 
(hereafter referred to as mean stand height) was calculated for the field $\left(\bar{h}_{F}\right)$ and photogrammetric measurements of the $30 \mathrm{~cm}$ GSD $\left(\bar{h}_{P 30}\right)$ and $10 \mathrm{~cm} \mathrm{GSD}\left(\bar{h}_{P 10}\right)$ aerial images.

The data were statistically processed using the program STATISTICA 7.1 (Hill \& Lewicki 2007 ) with a $5 \%$ significance level considered statistically significant. To compare the photogrammetric- and field-estimated mean stand heights, differences of the field- $\left(\bar{h}_{F-p}\right)$ and photogrammetric-estimated $\quad\left(\bar{h}_{P 30-p l}, \bar{h}_{P 10-p l}\right.$ ) mean plot heights were tested by analysing the variance of repeated measurements (RMANOVA, Davis 2002). Prior to RM-ANOVA testing, normality of data $\left(\bar{h}_{F-p l}, \bar{h}_{P 30-p l}\right.$, $\left.\bar{h}_{P 10-p l}\right)$ was checked using Shapiro-Wilk test (Shapiro \& Wilk 1965, Shapiro et al. 1968) which revealed that all data were normally distributed $(p>0.05)$ and therefore being eligible for testing by RM-ANOVA (Figure 4).

To evaluate the accuracy of the photogrammetric measurement method, the deviations $\left(\Delta_{30}\right.$ and $\left.\Delta_{10}\right)$ of the photogrammetrically estimated mean stand heights in relation to the field estimations were calculated for each subcompartment. The calculation for the digital aerial images at $30 \mathrm{~cm}$ GSD was as follows (eq. 2):

$\Delta_{30}=\bar{h}_{F}-\bar{h}_{P 30}$

The calculation for the digital aerial images at $10 \mathrm{~cm}$ GSD was as follows (eq. 3):

$$
\Delta_{30}=\bar{h}_{F}-\bar{h}_{P 10}
$$

To measure of the deviation of the photogrammetrically estimated heights compared to the field estimated heights, the root mean square error (RMSE) was also calculated for each subcompartment. The calculation for the photogrammetrically estimated heights of the $30 \mathrm{~cm}$ GSD aerial images was as follows (eq. 4):
$R M S E_{30}=\sqrt{\frac{\sum_{i=1}^{n}\left(\bar{h}_{F-p l}-\bar{h}_{P 30-p l}\right)}{n}}$

where $\mathrm{n}$ is the number of plots within each subcompartment. Similarly, for the digital im ages at $10 \mathrm{~cm}$ GSD, the calculation was (eq. 5):

$R M S E_{10}=\sqrt{\frac{\sum_{i=1}^{n}\left(\bar{h}_{F-p l}-\bar{h}_{P 10-p l}\right)}{n}}$
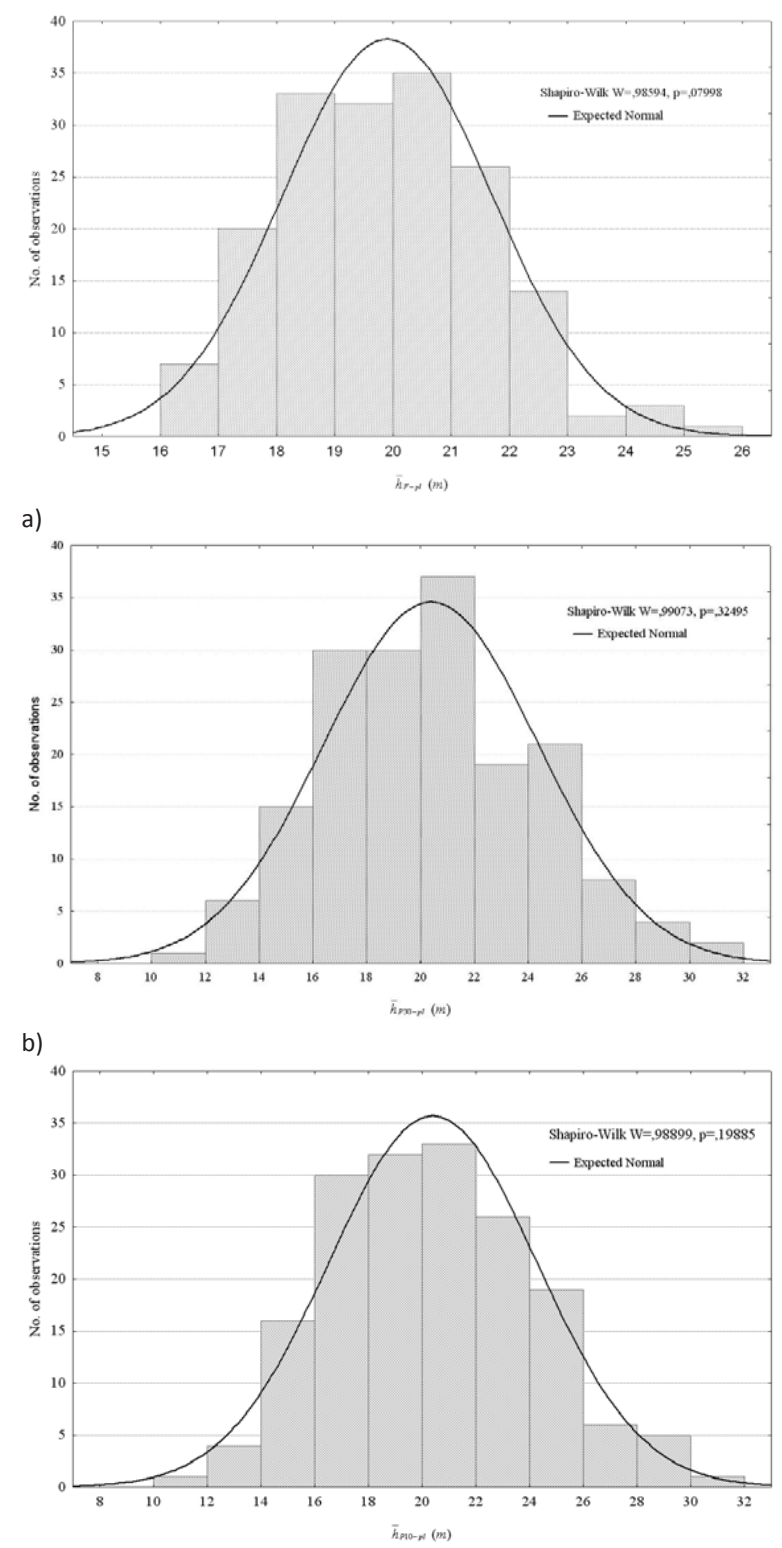

c)

Figure 4 Histograms of the mean plot heights estimated by field $\left(\mathrm{a}-\bar{h}_{F-p l}\right)$ and photogrammetric measurements $\left(\mathrm{b}-\bar{h}_{P 30-p l}\right.$, c- $\left.\bar{h}_{P 10}\right)$. 
where $\mathrm{n}$ is the number of plots within each subcompartment.

\section{Results}

Based on the field measured dbh and using the height curves, the heights of the 3135 trees within 183 sample plots were calculated. The same pattern of sample plots which overlaid upon the aerial images showed that a lower number of trees were detected and estimated on the images than in the field. A total of 2888 $(92 \%)$ trees were detected on the $10 \mathrm{~cm}$ GSD images, while a total of 2610 (83\%) trees were detected on the $10 \mathrm{~cm}$ GSD images.

Despite the photogrammetrically underestimated tree number, the test results (RM-ANOVA) between the mean stand heights estimated by different methods showed no statistically significant differences (Table 3, line 'Method').

However, statistically significant differences were found between the estimated 'patterns' of mean stand heights according to different methods (Table 3, line 'Method* Subcompartment'). This means that photogrammetric measurements did not produce consistent underestimations/overestimations of the estimated mean stand heights. Compared to field estimates, the heights obtained by photogrammetric method were underestimated in some subcompartments and overestimated in others, which is shown in Figure 5 and Table 4.

The results in table 4 show that the photogrammetric measurement of the aerial images of $30 \mathrm{~cm}$ GSD and $10 \mathrm{~cm}$ GSD yielded similar deviations of estimated mean stand heights $\left(\bar{h}_{P 30}, \bar{h}_{P 10}\right)$ compared to the field estimates $\left(\bar{h}_{F}\right)$. For example, the deviations $\left(\Delta_{30}\right)$ of $\bar{h}_{P 30}$ amounted to $0.35 \mathrm{~m}(1.59 \%)$ on average, whereas the deviations $\left(\Delta_{10}\right)$ of $\bar{h}_{P 10}$ amounted to $0.31 \mathrm{~m}(1.41 \%)$. The error of the photogrammetric estimates of the mean stand heights expressed by RMSE for the 30 cm GSD ( RMSE $_{30}$ ) images reached $3.55 \mathrm{~m}$ $(17.78 \%)$ on average, whereas on the RMSE for the $10 \mathrm{~cm}$ GSD (RMSE ${ }_{10}$ ) images reached $3.42 \mathrm{~m}(17.13 \%)$ compared to the field estimation.

Despite the fact that no statistically significant differences were observed between different methods (Table 3) and despite minor deviations $\left(\Delta_{30}, \Delta_{10}\right)$, photogrammetric measurements resulted in relatively high values of $\mathrm{RMSE}_{30}$ and $\mathrm{RMSE}_{10}$ of the mean stand heights compared to field estimates (Table 4). The RMSE of a particular stand (subcompartment) was calculated as the root mean square error (difference) of the mean plot heights in that particular stand, measured with the terrestrial and photogrammetric method (eq. 4, eq. 5). Consequently, the high RMSE values should be attributed to the difference of the mean plot heights measured with the different methods. According to Figure 6, two plots (49 and 50) of the $17 \mathrm{~b}$ subcompartment showed more significant deviations of the photogrammetrically estimated mean plot heights compared to field estimates. In both plots, the heights that were measured photogrammetrically were significantly overestimated in relation to field estimates, and they ranged between $3.66 \mathrm{~m}$ and

Table 3 The repeated measurements of the ANOVA test of the mean stand heights estimated by field $\left(\bar{h}_{F}\right)$ and photogrammetric measurements $\left(30 \mathrm{~cm} \mathrm{GSD}-\bar{h}_{P 30} ; 10 \mathrm{~cm} \mathrm{GSD}-\bar{h}_{P 10}\right)$

\begin{tabular}{llllll}
\hline Source of variability & $\begin{array}{l}\text { Sum of } \\
\text { squares }\end{array}$ & $\begin{array}{l}\text { Deegres of } \\
\text { freedom }\end{array}$ & Mean square & $F$ value & $p$ value \\
\hline Method & 9.4 & 2 & 4.7 & 1.309 & 0.2714 \\
Method*Subcompartment & 159.7 & 26 & 6.1 & 1.711 & 0.0185 \\
Error & 1141.9 & 318 & 3.6 & & \\
\hline
\end{tabular}




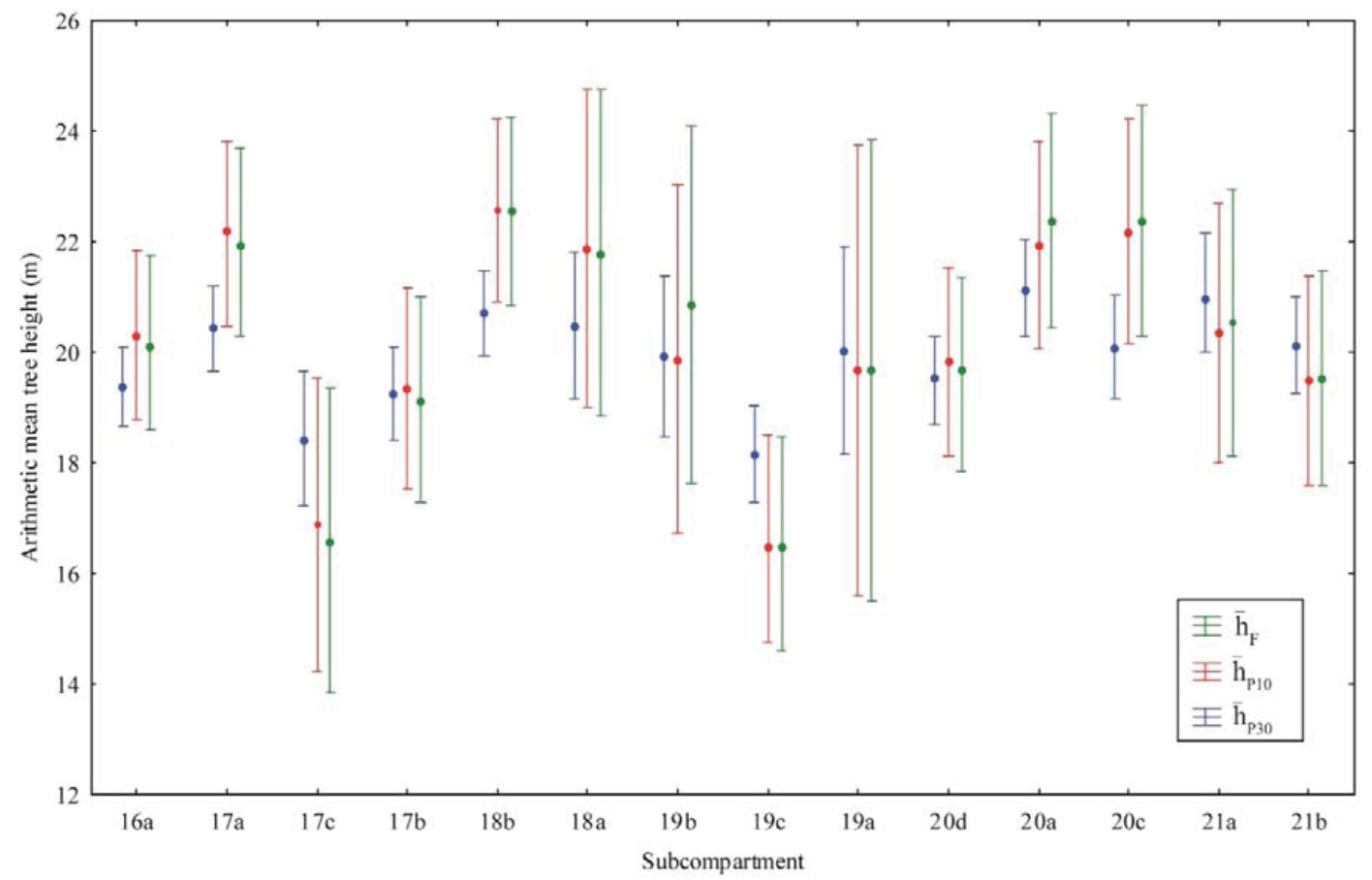

Figure 5 The mean stand heights estimated by field $\left(\bar{h}_{F}\right)$ and photogrammetric measurements $\left(\bar{h}_{P 30}\right.$, $\left.\bar{h}_{P 10}\right)$. The dots represent the estimated arithmetic mean tree heights of the subcompartments, whereas the vertical lines represent the $95 \%$ confidence intervals

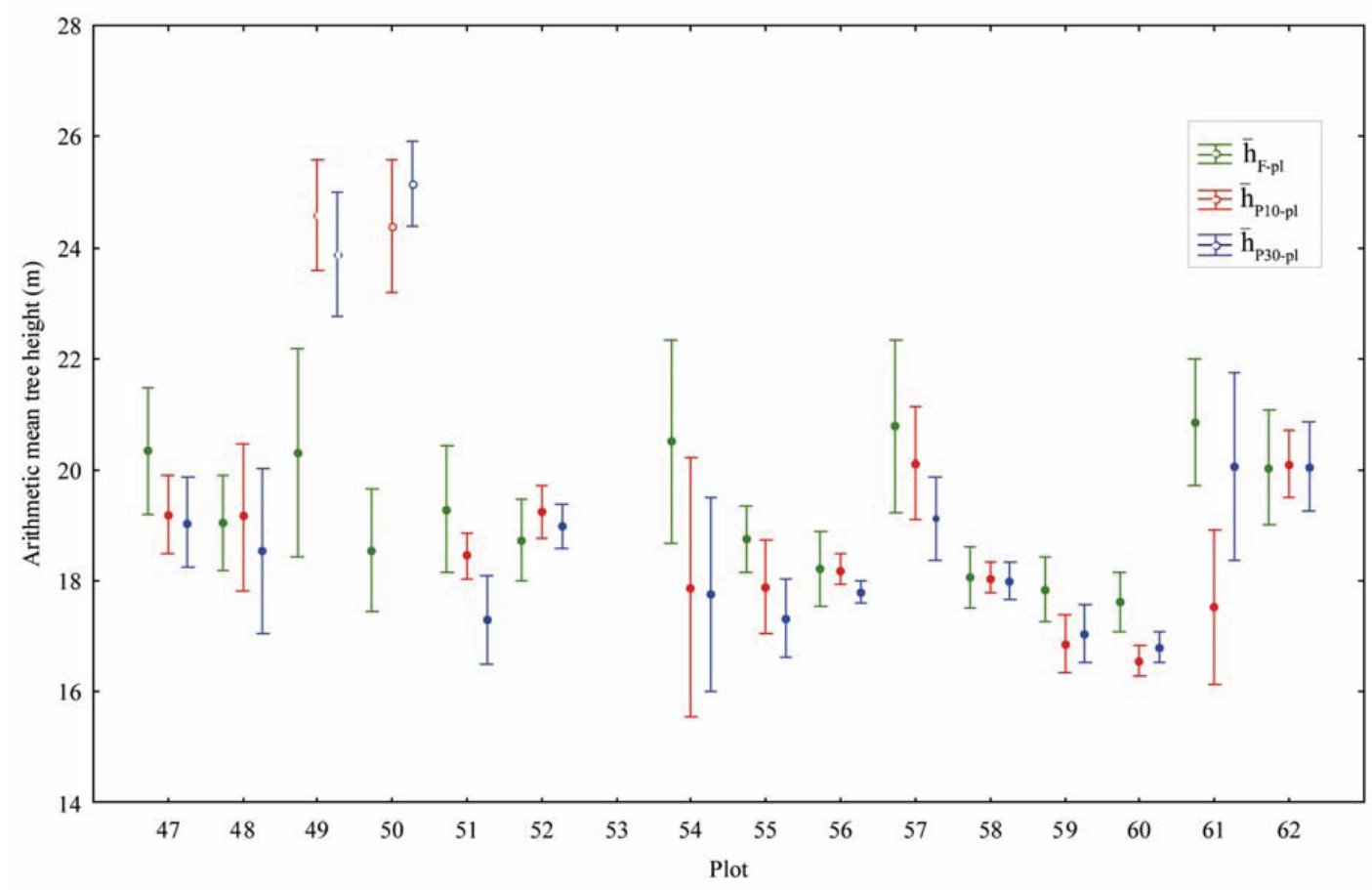

Figure 6 The mean plot heights of the subcompartment $17 \mathrm{~b}$ estimated by field $\left(\bar{h}_{F-p l}\right)$ and photogrammetric $\left(\bar{h}_{P 30-p l}, \bar{h}_{P 10-p l}\right)$ measurements. The dots represent the estimated arithmetic mean tree heights of the plots, whereas the vertical lines represent the $95 \%$ confidence intervals 
Table 4 The mean stand heights estimated by field $\left(\bar{h}_{F}\right)$ and photogrammetric measurements $\left(\bar{h}_{P 30}\right.$ and $\left.\bar{h}_{P 10}\right)$ with the errors of photogrammetric measurements presented by a deviation from the terrestrial measurement $\left(\Delta_{30}\right.$ and $\left.\Delta_{10}\right)$ and root mean square error $\left(\operatorname{RMSE}_{30}\right.$ and RMSE $\left.E_{10}\right)$

\begin{tabular}{llllllllllllllll}
\hline \multirow{2}{*}{$\begin{array}{l}\text { Subcom- } \\
\text { partment }\end{array}$} & $\begin{array}{l}\text { Management } \\
\text { class }\end{array}$ & $\mathrm{N}_{\text {plots }}$ & $\bar{h}_{F}$ & $\bar{h}_{P 30}$ & $\bar{h}_{P 10}$ & $\Delta_{30}$ & & $\Delta_{10}$ & & \multicolumn{2}{c}{$\mathrm{RMSE}_{30}$} & \multicolumn{2}{c}{$\mathrm{RMSE}_{10}$} \\
\hline 16a & E. beech & 22 & 19.38 & 20.18 & 20.31 & 0.80 & 4.1 & 0.94 & 4.8 & 3.78 & 19.5 & 3.89 & 20.1 \\
$17 \mathrm{a}$ & E. beech & 18 & 20.44 & 21.98 & 22.15 & 1.55 & 7.6 & 1.71 & 8.4 & 4.66 & 22.8 & 4.68 & 22.9 \\
$17 \mathrm{~b}$ & E. beech & 15 & 19.26 & 19.14 & 19.35 & -0.12 & -0.6 & 0.09 & 0.5 & 2.34 & 12.2 & 2.17 & 11.3 \\
$17 \mathrm{c}$ & C. hornbeam & 7 & 18.45 & 16.60 & 16.89 & -1.85 & -10.0 & -1.56 & -8.5 & 5.27 & 28.5 & 4.47 & 24.2 \\
$18 \mathrm{a}$ & S. oak & 6 & 20.50 & 21.80 & 21.89 & 1.30 & 6.3 & 1.39 & 6.8 & 5.20 & 25.4 & 5.15 & 25.1 \\
$18 \mathrm{~b}$ & E. beech & 18 & 20.73 & 22.55 & 22.58 & 1.83 & 8.8 & 1.86 & 9.0 & 3.18 & 15.3 & 3.13 & 15.1 \\
$19 \mathrm{a}$ & S. oak & 3 & 20.03 & 19.68 & 19.68 & -0.36 & -1.8 & -0.35 & -1.7 & 3.72 & 18.5 & 3.40 & 17.0 \\
$19 \mathrm{~b}$ & E. beech & 5 & 19.93 & 20.86 & 19.88 & 0.94 & 4.7 & -0.04 & -0.2 & 2.81 & 14.1 & 3.31 & 16.6 \\
19c & C. hornbeam & 14 & 18.16 & 16.54 & 16.64 & -1.63 & -9.0 & -1.52 & -8.4 & 2.29 & 12.6 & 2.23 & 12.3 \\
20a & S. oak & 14 & 21.17 & 22.38 & 21.95 & 1.20 & 5.7 & 0.77 & 3.7 & 3.96 & 18.7 & 3.71 & 17.5 \\
20c & E. beech & 12 & 20.10 & 22.38 & 22.19 & 2.29 & 11.4 & 2.10 & 10.4 & 4.26 & 21.2 & 4.12 & 20.5 \\
20d & C. hornbeam & 17 & 19.49 & 19.60 & 19.83 & 0.11 & 0.6 & 0.35 & 1.8 & 1.95 & 10.0 & 2.22 & 11.4 \\
21a & S. oak & 9 & 21.08 & 20.54 & 20.35 & -0.54 & -2.6 & -0.73 & -3.5 & 3.78 & 17.9 & 3.20 & 15.2 \\
21b & C. hornbeam & 23 & 20.13 & 19.53 & 19.49 & -0.60 & -3.0 & -0.64 & -3.2 & 2.44 & 12.1 & 2.12 & 10.6 \\
Average & & & & & & 0.35 & 1.59 & 0.31 & 1.41 & 3.55 & 17.78 & 3.42 & 17.13 \\
\hline
\end{tabular}

$6.59 \mathrm{~m}$. In almost all other plots, the photogrammetric heights were underestimated but in much lower amounts. However, the height underestimation obtained by the photogrammetric measurement ranged up to $-1 \mathrm{~m}$ with the exception of plots 51 and 54. In plot 51 the differences amounted to $-0.84 \mathrm{~m}$ (for $10 \mathrm{~cm}$ GSD) and $-1.98 \mathrm{~m}$ (for $30 \mathrm{~cm}$ GSD), whereas in plot 54 , they amounted to $-2.63 \mathrm{~m}$ (for 10 $\mathrm{cm}$ GSD) and $-2.74 \mathrm{~m}$ (for $30 \mathrm{~cm}$ GSD). Based on the previous findings and figure 6 the differences in height estimation for several plots $(49,50$ and 54) are largely responsible for the high RMSE values. For subcompartment $17 \mathrm{~b}$, the values were $2.17 \mathrm{~m}$ or $11.3 \%$ on average based on the aerial images of $10 \mathrm{~cm}$ GSD and $2.34 \mathrm{~m}$ or $12.2 \%$ on the aerial images of $30 \mathrm{~cm}$
GSD.

\section{Discussion}

As expected, a lower number of trees were photogrammetrically detected than by field survey, and this underestimation was greater for the aerial images of a lower spatial resolution (30 cm GSD). The results of this research are therefore in accordance with earlier studies on stereo-measurements (Korpela 2004). According to van Laar \& Akça (2007), the underestimation of the photogrammetrically derived number of trees usually occurs as a result of (a) 'clumped' crowns, which occur when two or more trees are interpreted as one, (b) over- 
shadowing on aerial images, which makes it impossible to identify individual trees, and (c) inability to measure understory trees.

However, the photogrammetrically underestimated tree number did not affect the accuracy of the photogrammetric measurement method at the stand level. A comparison of the obtained results did not reveal any statistically significant differences between the mean stand heights estimated in the field and those estimated by photogrammetric measurements for the digital aerial images of $30 \mathrm{~cm}$ GSD and 10 cm GSD (Table 3, line 'Method'). Therefore, the underestimation of the number of trees was most likely caused by 'clumped' crowns and not because of overshadowed and understory trees. This is understandable because the observed multi-aged stands consist of a series of small even-aged stands where understorey trees comprise a small portion of the total trees number.

Numerous research papers (Worley \& Landis 1954, Anttila 1998) conducted with classical (analogue and analytical) photogrammetric measurement methods have identified the issue of tree height underestimation. According to such studies, tree height underestimation occurs because tree tops cannot be accurately determined in analogue aerial photographs of low spatial resolution and because terrain elevations (next to the tree) cannot be read because of dense crown canopies. The underestimation of tree heights also commonly occurs with other remote sensing methods, such as the most up-to-date LiDAR technology, whether it is the height estimation of individual trees (e.g., Falkowski et al. 2006, Heurich 2008, Lin et al. 2012, Hunter et al. 2012) or of the mean stand heights (e.g., Næsset 2002b, Coops et al. 2007, Hyyppä et al. 2008, Alberti et al. 2013). The underestimations of LiDAR-estimated individual tree heights reported by above-mentioned studies ranged from 0.43 to $1.20 \mathrm{~m}$, whereas underestimations of LiDAR-estimated mean stand heights ranged up to $3.30 \mathrm{~m}$. The magnitude of underestimation, i.e. the accuracy of LiDARestimated tree heights depends on many factors such as: LiDAR system characteristics (pulse density, footprint diameter, laser pulse divergence, scanning angle), the algorithms used for data processing, and forest characteristics (tree species, stand density, percentage and height of understory and ground vegetation, etc.) (Нyyppä et al. 2008, Balenović et al. 2013). According to the results obtained from this research (Figure 5, Table 4), the method did not lead to constant and systematic underestimations of tree heights. Compared to field estimates, the photogrammetric mean stand heights $\left(\bar{h}_{P 30}\right.$ and $\left.\bar{h}_{P 10}\right)$ were underestimated in some subcompartments and overestimated in others, but within the limits of statistically significant differences. In this case, therefore, it may be assumed that the systematic tree height underestimation is reduced by applying digital aerial images of high spatial resolution that can more accurately determine the tree tops and enabling DTM to read the terrain elevations (tree 'bottoms') in densely canopied stands.

In addition, the photogrammetric measurements for the aerial images of $30 \mathrm{~cm}$ GSD and $10 \mathrm{~cm}$ GSD yielded similar deviations $(\Delta$, RMSE) of the estimated mean stand heights compared to field estimations (Table 4). Therefore, it may be concluded that the $30 \mathrm{~cm}$ GSD aerial images provided the possibility of photogrammetric measurements of the mean stand heights with accuracy similar to the $10 \mathrm{~cm}$ GSD aerial images. Due to the fact that the same area can be covered with a considerably smaller number of images, the $30 \mathrm{~cm}$ GSD aerial images are also financially more favourable than the $10 \mathrm{~cm}$ GSD aerial images. For the purpose of this research, the price of the 'high' aerial survey when the 21 aerial images of 30 cm GSD were collected was approximately 1.4 $€ /$ ha, whereas the price of the 'low' aerial survey when the 7 aerial images of $10 \mathrm{~cm}$ GSD were collected was almost five times higher and reached approximately $7.0 € /$ ha.

Although statistically significant differences were not found between the two measurement methods and despite minor deviations $\left(\Delta_{30}\right.$ 
and $\left.\Delta_{10}\right)$, the photogrammetric measurements yielded relatively high RMSE values RMSE $_{30}$ and $\mathrm{RMSE}_{10}$ ) of the mean stand heights compared to field estimates (Table 4). Relatively high values of RMSE should be attributed to the difference of the mean plot heights measured within several specific plots. As shown in Figure 6, there were only a few differences in plot height between photogrammetric- and field-estimated heights that resulted in higher RMSE values of the mean stand height.

The reasons for major deviations between the photogrammetric and field mean tree heights of individual plots may have resulted from (i) an error of DTM, (ii) an error in GPS positioning, i.e. spatial (horizontal) deviations of photogrammetric plots compared to field plots caused by the GPS receiver, (iii) an error of the height curves used in the field estimation of tree height. Although the DTM has a specific high vertical accuracy $\left(\mathrm{RMSE}_{\mathrm{z}}=0.04 \mathrm{~m}\right)$, its accuracy in forested areas may be lower. It is well known that the DTM of forested areas created with classic photogrammetric methods has a lower accuracy because of the ground being obscured by vegetation (Järndstedt et al. 2012, White et al. 2013). As it shown in Figure 2, the accuracy assessment of DTM was conducted based on 15 ground control points, and most of them (11) were located in non-forested areas. For four ground control points located near the forest or in the forest differences between field and DTM-derived elevation (z) were just slightly greater $(0.04-0.06 \mathrm{~m})$ than for ground control points located in non-forested areas. In addition to vertical accuracy, the influence on tree height measurements may have affected the horizontal accuracy of the DTM as well. Namely, horizontal errors cause vertical errors if the terrain has slopes (Höhle \& Höhle 2009). Unfortunately, the horizontal error of the DTM was not provided by the manufacturer. Because the research area has a distinct terrain relief (Figure 3) and considering the previously mentioned issues, it may be assumed that the DTM for particular parts of the terrain did not provide accurate elevation data as was specified. Therefore, for those parts of the terrain, higher errors of photogrammetrically estimated heights of individual trees and mean plot heights may be expected. These errors were positive for some plots and negative for others. Positive and negative errors most likely mutually cancelled each other at the stand level, as the photogrammetric mean stand height results were almost equal to field stand heights. Such underestimations or overestimations of several photogrammetric mean plot heights were reflected in the RMSE values of the mean stand height. Gagnon et al. (1993) and Zagalikis et al. (2005) reached a similar conclusion in their research. They stated that the accuracy of the photogrammetric measurement of tree heights was affected by the accuracy of the DTM. Because the same DTM was used in the photogrammetric measurements $(30 \mathrm{~cm}$ GSD and 10 $\mathrm{cm}$ GSD) and because similar deviations were observed in both measurements in plots of the subcompartment 17b (Figure 6), the observed deviations were likely caused by the DTM.

Errors in detecting tree bottom elevations and errors in tree height estimations may be decreased by using more accurate DTMs. The previously mentioned LiDAR technology, which uses laser pulses to penetrate the forest canopy to the ground, allows for the acquisition of dense and accurate ground elevation data. Therefore, the DTM generated from LiDAR data is of higher accuracy than the DTM generated from photogrammetric methods (Vega \& St-Onge 2008, White et al. 2013). However, the visual interpretation of forest attributes, such as tree species, health status, and maturity, cannot currently be estimated from LiDAR data (White et al. 2013). To utilise the advantages of each method, the option to combine photogrammetry and LiDAR for forest inventory purposes has attracted the attention of many researchers (Popescu et al. 2004, StOnge et al. 2004, 2008, Holmgren et al. 2008, Véga \& St-Onge 2008, Bohlin et al. 2012, Nurminen et al. 2013). For example, St-Onge et al. 
(2004) proposed the photogrammetric- LiDAR ('photo-LiDAR') approach to estimate tree height by calculating the difference between the photogrammetrically detected tree tops and tree bottoms derived from LiDAR DTM. They underestimated the photo-LiDAR tree heights on average by $0.59 \mathrm{~m}$ compared to the field measured heights. In this case, however, the accuracy of tree height estimation (tree top determination) may be increased by applying the digital aerial images of a higher spatial and radiometric resolution. The same "photoLiDAR' approach was later used by Véga \& St-Onge (2008) to estimate tree height growth. Currently, the only advantage of choosing photogrammetric DTM over LiDAR DTM is the lower image acquisition cost in relation to LiDAR data acquisition (White et al. 2013).

The differences between the photogrammetric- and field-estimated mean plot heights may also be a result of error in GPS positioning, i.e. spatial deviations in the photogrammetric plots in relation to the terrestrial plots caused by GPS receiver error that occurs as a result of weaker signal reception in densely canopied stands. In general, the accuracy of the GPS receiver positions decreased with increasing forest stand density and shorter observation periods (Næsset \& Gjevestad 2008). Therefore, it may be assumed that in this case, the positional GPS error, or the horizontal error of the recorded centres ( $\mathrm{x}, \mathrm{y}$ coordinates) of the terrestrial sample plots, was most likely higher than the quoted error of 2-5 $\mathrm{m}$ for ideal conditions. As previously stated, the photogrammetric plots were 'set up' on the basis of $\mathrm{x}$ and $\mathrm{y}$ coordinates of field plot centres recorded by the GPS receiver. In the plots with a greater GPS error, different groups of trees may be observed during field and photogrammetric measurements. This may result in different values of field and photogrammetric mean plot heights.

Another possible reason for the deviations between the photogrammetric- and field-estimated mean plot heights may be attributed to the erroneous estimation of field tree heights
$\left(h_{\mathrm{F}}\right)$ since they were not directly measured but were estimated from the fitted height curves. All four height curves used for the field estimates (Table 1) commonly showed that the tree height is slightly overestimated for trees with dbh smaller than $20 \mathrm{~cm}$, and slightly underestimated for trees with dbh greater than $20 \mathrm{~cm}$.

However, the proposed photogrammetric stereo-measurement method of mean stand height provided more accurate results compared to the results of previous research, whether the research was conducted with classical (analogue and analytical) photogrammetric measurement methods (Benko 1993, Næsset 1996, Kovats 1997, Anttila 1998, Eid et al. 2004, Magnusson \& Fransson 2005) or digital aerial images with the application of DPW (Korpela 2004, Magnusson et al. 2007). These results are even more important if we consider that this research was conducted on privately owned forests of a rather heterogeneous structure, which requires more demanding photogrammetric measurements and photointerpretations. For example, by using photogrammetric measurements of tree heights on analogue stereo instruments, Benko (1993) obtained the following average deviations from field-measured heights per tree species: $-0.8 \%$ for black alder, $6.0 \%$ for narrow-leaved ash and $-8.4 \%$ for black locust. Eid et al. (2004) listed the average deviations of photogrammetric heights of dominant trees from -5.6 and $-5.5 \%$ for the entire research area, whereas the deviations of photogrammetric heights of individual stands ranged from -29 to $26 \%$ compared to field-estimated heights. Magnusson et al. (2007) conducted rare and important research operations using the manual method of photogrammetric measurement and photointerpretation of digital aerial images on DPW, and four independent interpreters photogrammetrically measured the mean stand heights using the Z/I DMC digital aerial images with a spatial resolution of $48 \mathrm{~cm}$ and an average deviation of $0.9 \mathrm{~m}$ compared to the field measurements. The two aggravating circumstances they mentioned included poor 
spatial resolution of the digital aerial images and photogrammetric software that was not 'user-friendly' enough for operational use.

However, the constant development of computer technology has produced a significant advancement in photogrammetric software (Balenović et al. 2011). The software used in this research (PHOTOMOD and Global Mapper), when combined with the DPW, are designed as 'user-friendly' so that a relatively low level of photogrammetry expertise is required. The PHOTOMOD software enables the simple creation of digital image projects (stereo models), easy manipulation of multiple digital images, and many other features that facilitate photogrammetric stereo-measurement and photo-interpretation.

\section{Conclusions}

For the stereo-models of CIR digital aerial images of a high spatial resolution (30 $\mathrm{cm}$ GSD and $10 \mathrm{~cm} \mathrm{GSD),} \mathrm{the} \mathrm{DTM} \mathrm{and} \mathrm{DPW} \mathrm{using} \mathrm{the}$ appropriate software (PHOTOMOD and Global Mapper) were used to estimate the mean stand heights. A comparison (RM-ANOVA) of the obtained results did not reveal any statistically significant differences $(p>0.05)$ between the field-estimated and photogrammetric- estimated mean stand heights using the $30 \mathrm{~cm}$ GSD and $10 \mathrm{~cm}$ GSD digital aerial images. The systematic tree height estimation pinpointed by numerous previous studies is reduced in this research by applying digital aerial images of high spatial resolution that can more accurately determine the tree tops and enabling DTM to read the terrain elevations (tree 'bottoms') in densely canopied stands. Furthermore, the photogrammetric measurements for the aerial images of $30 \mathrm{~cm}$ GSD and $10 \mathrm{~cm}$ GSD yielded similar deviations $(\Delta, \mathrm{RMSE})$ of the estimated mean stand heights compared to field estimations. This indicates that the $30 \mathrm{~cm}$ GSD aerial images provide the possibility of photogrammetric measurement of the mean stand heights with accuracy similar to the $10 \mathrm{~cm}$ GSD aerial images. In addition, the $30 \mathrm{~cm}$ GSD aerial images are also financially more favourable.

In conclusion, the results show that the method used in this research may be used operationally to estimate mean stand heights. Assuming that certain conditions are met (e.g., high precision DTM), the method may also be used to estimate the height of individual trees with satisfactory accuracy.

\section{Acknowledgments}

This research was realised as part of projects: 'Growth and development of forest in different ecological conditions and under different management' and 'Monitoring the forest health status using remote sensing methods' both financed by the Ministry of Science, Education and Sport of the Republic of Croatia. Furthermore, research has been supported in part by Croatian Science Foundation under the project 2492 ('Estimating and Forecasting Forest Ecosystem Productivity by Integrating Field Measurements, Remote Sensing and Modelling' - EFFEctivity) and by Croatian Forest Ltd within the project 'Application of digital photogrammetry in practical forest management'.

\section{References}

Alberti G., Boscutti F., Pirotti F., Bertacco C., De Simon G., Sigura M., Cazorzi F., Bonfanti P., 2013. A LiDARbased approach for a multi-purpose characterization of Alpine forests: an Italian case study. iForest - Biogesciences and Forestry 6: 156-168. DOI: 10.3832/ ifor0876-006.

Anttila P., 1998. On the accuracy of treewise attributes obtained by analytical stereoplotter and aerial images. MSc thesis, University of Joensuu, Faculty of Forestry, Joensuu, $36 \mathrm{p}$.

Anttila P., 2005. Assessment of manual and automated methods for updating stand-level forest inventories based on aerial photography. $\mathrm{PhD}$ thesis, University of Joensuu, Faculty of Forestry, Joensuu, 42 p. Web: http:// www.metla.fi/dissertationes/df9.pdf. Accessed: 2013.

Arcangeli C., Klopf M., Hale S.E., Jenkins T.A.R., Hasenauer H., 2013. The uniform height curve method 
for height-diameter modelling: an application to Sitka spruce in Britain. Forestry 87: 177-186. DOI: 10.1093/ forestry/cpt041.

Balenović I., Marjanović H., Benko M., 2010. Primjena aerosnimaka u uređivanju šuma u Hrvatskoj [Application of aerial photographs in forest management in Croatia]. Šumarski list 134(11-12): 623-631.

Balenović I., Seletković A., Pernar R., Marjanović H., Vuletić D., Paladinić E., Kolić J., Benko M., 2011. Digital photogrammetry - State of the art and potential for application in forest management in Croatia. Southeast European forestry 2 (2): 81-93. DOI: 10.15177/ seefor.11-09.

Balenović I., Seletković A., Pernar R., Marjanović H., Vuletić D., Benko M., 2012. Comparison of classical terrestrial and photogrammetric method in creating management division. In Pentek T., Poršinsky T., Šporčić M. (eds) 'Forest Engineering - Concern, Knowledge and Accountability in Today's Environment", 8-12 October 2012, Dubrovnik. Forestry Faculty of University Zagreb, $13 \mathrm{p}$.

Balenović I., Alberti G., Marjanović H., 2013. Airborne Laser Scanning - the Status and Perspectives for the Application in the South-East European Forestry. Southeast European forestry 4 (2): 59-79. DOI: $10.15177 /$ seefor.13-07.

Benko M., 1993. Procjena taksacijskih elemenata sastojina na infracrvenim kolornim aerosnimkama [Assessment of stands elements on colour infrared aerial photographs]. Glasnik za šumske pokuse 29: 199-274.

Benko M., Balenović I., 2011. Prošlost, sadašnjost i budućnost primjene metoda daljinskih istraživanja pri inventuri šuma u Hrvatskoj [Past, present and future of application of remote sensing methods in Croatian forest inventory]. Šumarski list 135(13): 272-281.

Bohlin J., Wallerman J., Fransson J.E.S., 2012. Forest variable estimation using photogrammetric matching of digital aerial images in combination with a high-resolution DEM. Scandinavian Journal of Forest Research 27(7): 692-699. DOI: 10.1080/02827581.2012. 686625.

Coops N.C., Hilker T., Wulder M.A., St-Onge B., Newnham G., Siggins A., Trofymow J.T., 2007. Estimating canopy structure of Douglas-fir forest stands from discrete-return LiDAR. Trees 21(3): 295-310. DOI: 10.1007/s00468-006-0119-6.

Davis C.S., 2002. Statistical Methods for the Analysis of Repeated Measurements. Springer, New York, 415 p.

Eid T., Gobakken T., Næsset E., 2004. Comparing stand inventories for large areas based on photo-interpretation and laser scanning by means of cost-plus-loss analyses. Scandinavian Journal of Forest Research 19(6): 512523. DOI: 10.1080/02827580410019463.

Falkowski M.J., Smith A.M.S., Hudak A.T., Gessler P.E., Vierling L.A., Crookston N.L., 2006. Automated estimation of individual conifer tree height and crown diameter via two-dimensional spatial wavelet analysis of lidar data. Canadian Journal of Remote Sensing 32(2): 153-161. DOI: 10.5589/m06-005.
Ferdinent J.J., Padmanaban R.C., 2013. Development of a methodology to estimate biomass from tree height using airborne digital image. International Journal of Advanced Remote Sensing and GIS 2(1): 49-58.

Gagnon P.A., Agnard J.P., Nolette C., 1993. Evaluation of a soft-copy photogrammetry system for tree-plot measurements. Canadian Journal of Remote Sensing 23(9): 1781-1785. DOI: 10.1139/x93-225.

Gruber M., Ponticellia M., Bernögger S., Leberl L., 2008. Ultracamx, the Large Format Digital Aerial Camera System by Vexcel Imaging/Microsoft. In: Chen J., Jiang J., Baudoin A. (eds.). Proceedings of ISPRS XXIst Congress "Silk Road for Information from Imagery", 3-11 July 2008, Beijing. ISPRS, Vol. XXXVII, Part B1, pp. 665-670.

Heurich M., 2008. Automatic recognition and measurement of single trees based on data from airborne laser scanning over the richly structured natural forests of the Bavarian Forest National Park. Forest Ecology and Management 255(7): 2416-2433. DOI: 10.1016/ j.foreco. 2008.01.022.

Hill T., Lewicki P., 2007. STATISTICS: Methods and Applications. StatSoft, Tulsa, OK.

Höhle J., Höhle M., 2009. Accuracy assessment of digital elevation models by means of robust statistical methods. ISPRS Journal of Photogrammetry and Remote Sensing 64(4): 398-406. DOI: 10.1016/ j.isprsjprs.2009.02.003.

Holmgren J., Persson A., Söderman U., 2008. Species identification of individual trees by combining high resolution LIDAR data with multispectral images. International Journal of Remote Sensing 29(5): 1537-1552. DOI: $10.1080 / 01431160701736471$.

Honkavaara E., Arbiol R., Markelin L., Martinez L., Cramer M., Bovet S., Chandelier L., Ilves R., Klonus S., Marshal P., Shläpfer D., Tabor M., Thom C., Veje N., 2009. Digital airborne photogrammetry - a new tool for quantitiative remote sensing? A state-of-the-art review on radiometric aspects of digital photogrammetric images. Remote Sensing 1(3): 577-605. DOI: 10.3390/ rs 1030577 .

Hoxha B., 2012. Two-phased inventory of standing volume in mountain forests with the use of aerial photographs. Folia Forestalia Polonica 54(2): 123-133.

Hunter M.O., Keller M., Vitoria D., Morton D.C., 2012. Tree height and tropical forest biomass estimation. Biogeosciences Discussions 10: 10491-10529. DOI: 10.5194/bgd-10-10491-2013.

Hyyppä J., Hyyppä H., Leckie D., Gougeon F., Yu X., Maltamo M., 2008. Review of methods of small-footprint airborne laser scanning for extracting forest inventory data in boreal forests. International Journal of Remote Sensing 29(5): 1339-1366. DOI: 10.1080/014311607 01736489.

Järndstedt J., Pekkarinen A., Tuominen S., Ginzler C., Holopainen M., Viitala R., 2012. Forest variable estimation using a high-resolution digital surface model. ISPRS Journal of Photogrammetry and Remote Sensing 74: 78-84. DOI: 10.1016/j.isprsjprs.2012.08.006. 
Ke Y., Quackenbush L.J., 2011. A review of methods for automatic individual tree-crown detection and delineation from passive remote sensing. International Journal of Remote Sensing 32(17): 4725-4747. DOI: $10.1080 / 0$ 1431161.2010 .494184$.

Korpela I., 2004. Individual tree measurements by means of digital aerial photogrammetry. Silva Fennica mon. 3: $1-93$.

Korpela I., Anttila P., 2004. Appraisal of the mean height of trees by means of image matching of digitised aerial photographs. Photogrammetric Journal of Finland 19(1): 23-36

Kovats M., 1997. A large-scale aerial photographic technique for measuring tree heights on long-term forest installations. Photogrammetric Engineering and Remote Sensing 63(6): 741-747.

Lemmens M., 2011. Digital Photogrammetric Workstations - Status and Features. GIM International 25: 12. Web: http://www.gim-international.com/issues/articles/ id1797-Digital Photogrammetric Workstations.html. Accessed 2013.

Lin Y., Hyyppä J., Kukko A., Jaakkola A., Kaartinen H., 2012. Tree height growth measurement with singlescan airborne, static terrestrial and mobile laser scanning. Sensors 12(9): 12798-12813. DOI: 10.3390/ s120912798.

Linder W., 2009. Digital photoogrammetry - A practical course. Springer, Berlin. 220 p. DOI: 10.1007/978-3540-92725-9.

Magnusson M., Fransson J.E.S., 2005. Evaluation of aerial photo-interpretation for estimation of forest stem volume at stand level. In: Olsson $\mathrm{H}$ (ed.) "Operational Tools in Forestry Using Remote Sensing Techniques", 31 May-3 June, 2005, Borås. Swedish Forest Agency, Report 8, Vol C, pp. 102-106.

Magnusson M., Fransson J.E.S., Olsson H., 2007. Aerial photo-interpretation using Z/I DMC images for estimation of forest variables. Scandinavian Journal of Forest Research 22(3): 254-266. DOI: 10.1080/02827580701 262964.

Meyer P., Staenz K., Itten K.I., 1996. Semi-automated procedures for tree species identification in high spatial resolution data from digitized colour infrared-aerial photography. ISPRS Journal of Photogrammetry and Remote Sensing 51(1): 5-16. DOI: 10.1016/09242716(96)00003-2.

Michailoff I., 1943. Zahlenmässiges Verfahren für die Ausführung der Bestandeshöhenkurven. Cbl. und Thar. Forstl. Jahrbuch 6: 273-279.

Morgan J.L., Gergel S.E., Coops N.C., 2010. Aerial photography: A rapidly evolving tool for ecological management. BioScience 60(1): 47-59. DOI: 10.1525/ bio.2010.60.1.9.

Næsset E., 1996. Determination of number of stems in coniferous forest stands by means of aerial photo-interpretation. Scandinavian Journal of Forest Research 11(1): 76-84. DOI: 10.1080/02827589609 382914.

Næsset E., 2002a. Determination of mean tree height of forest stands by means of digital photogrammetry. Scandinavian Journal of Forest Research 17(5): 446-459. DOI: $10.1080 / 028275802320435469$.

Næsset E., 2002b. Predicting forest stand characteristics with airborne scanning laser using a practical two-stage procedure and field data. Remote Sensing of Environment 80(1): 88-99. DOI: 10.1016/S00344257(01)00290-5.

Næsset E., Gjevestad J.G., 2008. Performance of GPS Precise Point Positioning Under Conifer Forest Canopies. Photogrammetric Engineering \& Remote Sensing 74: 661-668. DOI: 10.14358/ PERS.74.5.661.

Nurminen K., Karjalainen M., Yu X., Hyyppä J., Honkavaara E., 2013. Performance of dense digital surface models based on image matching in the estimation of plot-level forest variables. ISPRS Journal of Photogrammetry and Remote Sensing 83: 104-115. DOI: 10.1016/ j.isprsjprs.2013.06.005.

Paine D.P, Kiser J.D., 2012. Aerial photography and image interpretation. Third Edition. John Wiley \& Sons, Inc., Hoboken, New Jersey. DOI: 10.1002/9781118110997.

Pernar R., 1994. Način i pouzdanost određivanja oštećenosti hrasta lužnjaka (Quercus robur L.) na infracrvenim kolornim (ICK) aerosnimkama [Method and reliability of assessing pedunculate oak (Quercus robur L.) damage on colour infrared (CIR) aerial photographs]. Glasnik za šumske pokuse 31: 1-34.

Pernar R., Seletković A., Ančić M., 2007a. Utvrđivanje oštećenosti šuma Spačvanskog bazena primjenom infracrvenih kolornih aerosnimaka [Assessing forest damage in the Spačva basin with colour infrared aerial photographs]. Šumarski list 131(7-8): 315-322.

Pernar R., Ančić M., Seletković A., 2007b. Primjena ICK aerosnimaka za utvrđivanje oštećenosti šuma na području UŠP Gospić [Application of colour infrared aerial photographs for the assessment of forest damage in the Gospić Forest Administration]. Šumarski list 131(11-12): 507-521.

Popescu S.C., Wynne R.H., 2004. Seeing the Trees in the Forest: Using Lidar and Multispectral Data Fusion with Local Filtering and Variable Window Size for Estimating Tree Height. Photogrammetric Engineering and Remote Sensing 70(5): 589-604. DOI: 10.14358/ PERS.70.5.589.

Sandau R., 2010. Digital Airborne Camera, Introduction and Technology. Springer, Dordrecht, 343 p. DOI: 10.1007/978-1-4020-8878-0.

Shapiro S.S., Wilk M.B., 1965. An analysis of variance test for normality (complete samples). Biometrika 52: 591611. DOI: 10. 1093/biomet/52.3-4.591.

Shapiro S.S., Wilk M.B., Chen H. J., 1968. A comparative study of various tests for normality. Journal of the American Statistical Association 63: 1343-1372. DOI: 10.1080/01621459.1968.10480932.

Spencer R.D., Hall R.J., 1988. Canadian large-scale aerial photographic systems (LSP). Photogrammetric Engineering and Remote Sensing 54(4): 475-482.

St-Onge B., Jumelet J., Cobello M., Véga C., 2004. Mea- 
suring individual tree height using a combination of stereophotogrammetry and lidar. Canadian Journal of Forest Research 34: 2122-2130. DOI: 10.1139/x04-093.

St-Onge B., Véga C., Fournier R.A., Hu Y., 2008. Mapping canopy height using a combination of digital stereo-photogrammetry and lidar. International Journal of Remote Sensing 29(11): 3343-3364. DOI: 10.1080/014 31160701469040 .

Tuominen S., Pitkänen J., Balazs A., Korhonen K. T., Hyvönen P., Muinonen E., 2014. NFI plots as complementary reference data in forest inventory based on airborne laser scanning and aerial photography in Finland. Silva Fennica 48 (2): article id 983. DOI: 10.14214/ sf.983.

Van Laar A., Akça A., 2007. Forest mensuration. Springer, Dordrecht, 376 p. DOI: 10.1007/978-1-4020-5991-9.

Véga C., St-Onge B., 2008. Height growth reconstruction of a boreal forest canopy over a period of 58 years us- ing a combination of photogrammetric and lidar models. Remote Sensing of Environment 112(4): 1784-1794. DOI: 10.1016/j.rse.2007.09.002.

White J.C., Wulder M.A., Vastaranta M., Coops N.C., Pitt D., Woods M., 2013. The utility of image-based point clouds for forest inventory: A comparison with airborne laser scanning. Forests 4(3): 518-536. DOI: 10.3390/ f4030518.

Worley D.P., Landis G.H., 1954. The accuracy of height measurements with parallax instruments on 1:12000 photographs. Photogrammetric Engineering 20(1): 823829.

Zagalikis G., Cameron A.D., Miller D.R., 2005. The application of digital photogrammetry and image analysis techniques to derive tree and stand characteristics. Canadian Journal of Forest Research 35(5): 1224-1237. DOI: $10.1139 / \mathrm{x} 05-030$. 
